\title{
Dissolution Kinetics in Polymer-Bound and Polymer-Blended Photo-Acid Generators
}

\author{
Hiroki Yamamoto ${ }^{\text {a, }}{ }^{*}$, Takahiro Kozawa, ${ }^{\text {a, }}$ and Seiichi Tagawa ${ }^{\text {a, b }}$, \\ ${ }^{\mathrm{a}}$ The Institute of Scientific and Industrial Research, Osaka University, \\ 8-1 Mihogaoka, Ibaraki, Osaka 567-0047, Japan \\ ${ }^{\mathrm{b}}$ Japan Science and Technology Agency, CREST clo Osaka University \\ "E-mail address: hiroki@sanken.osaka-u.ac.jp
}

\begin{abstract}
In the fabrication beyond $16 \mathrm{~nm}$ node, the uniform distribution of acid generators in resist matrix is a serious concern. Recently, the incorporation of acid generators to polymers via covalent bonds has attracted much attention in order to overcome the compatibility problem of acid generators with polymers and reduce the diffusion lengths of acid, which leads to high resolution and low line edge roughness (LER). However, understanding of the resist dissolution kinetics in polymer-bounded and polymer-blended photo-acid generator (PAG) for extreme ultraviolet (EUV) lithography is insufficient. Therefore, it is significantly important to clarify the effect of binding acid generator with polymer on the dissolution kinetics. In this study, dissolution kinetics in polymer-bound and polymer-blended PAG was investigated to understand inherent EUV resist characteristics. The development rate $\mathrm{R}(\mathrm{E}, \mathrm{Z})$ at different depth position in resist film was determined in polymer-bounded and polymer-blended PAG using resist development analyzer (RDA-800EUV) measurement system. The difference of $\mathrm{R}(\mathrm{E}, \mathrm{Z})$ in polymer-bounded and polymer-blended PAG was observed. Also, the preliminary evaluation of resist profile for EUV chemically amplified resists was performed by using PROLITH and parameters obtained with EUV exposure tool. Furthermore, the resist patterns were produced by electron beam and the SEM observation results were compared with the PROLITH simulation results.
\end{abstract}

Keywords: EUV lithography, polymer-bound PAG, polymer-blended PAG, dissolution kinetics, PROLITH

\section{Introduction}

Beyond the $16 \mathrm{~nm}$ node, extreme ultraviolet (EUV) lithography is the most potential candidate for the mass production of the $16 \mathrm{~nm}$ DRAM half pitch and below. In ITRS 2008 road map, the target of resist performance in EUV lithography is set to be as following. Resolution, Line width roughness (LWR) and sensitivity requirements for DRAM half pitch are $16 \mathrm{~nm}, 0.9 \mathrm{~nm} 3 \sigma, 10 \mathrm{~mJ} / \mathrm{cm}^{2}$, respectively.[1] Thus, the requirement of resist performance individually has become very strict demand. Moreover, it becomes the most difficult task to simultaneously fulfill these requirements because there is a trade-off among these requirements in EUV lithography.[2] In order to overcome these problems concurrently, it is very important to separately understand reaction mechanisms of the resist pattern formation and inherent resist characteristics such as acid generation efficiency, dissolution kinetics, deprotection reaction and so on. Also, novel chemically amplified resist materials must be developed.

In pattern formation of chemically amplified resists, the energy is first deposited on resist materials by incident radiation such as EUV radiation. Using the accumulated energy, acids are generated. The acids catalyze pattern formation 
reactions during PEB via typically the deprotection reaction of polymers, causing the change in alkaline solubility of the resist in exposed areas. [3] It is indispensable for feasibility of EUV lithography to grasp basic chemistry of resist matrices in all stage. With the reduction in feature sizes, the acid generation efficiency and chemical reactions such as deprotection reaction and dissolution kinetics in resist films becomes critical to accomplish high resolution and high sensitivity. Especially, dissolution kinetics of resist films is a key factor to pattern formation. Therefore, it is important to understand dissolution kinetics for the feasibility of EUV lithography.

So far, we have estimated acid generation efficiencies in resist matrices and elucidated the reaction mechanism of chemically amplified resist for ionizing radiation such as Electron beam (EB) and EUV. [4-6, 9] The acid generation mechanism for EUV resists is analogous to that of EB resists. [7-9] However, the absorption of incident EUV photon conforms to Lambert's Law in EUV resists as well as $\mathrm{KrF}$ and ArF photoresists. Thus, it is clarified that EUV resists have some similarity to those in both photoresists and EB resists.

Currently, chemically amplified resist is expected to work well in EUV lithography in order to accomplish mass production. [10, 11] However, the phase separation between the resist components has been suggested $[12,13]$ or directly observed. [14] Thus, chemically amplified resists have faced serious problems. In chemically amplified EB and EUV resists, the energy of radiation is mostly deposited on the polymer matrices via ionization processes. When EUV photons enter resist materials, polymers are ionized. By ionization, polymer radical cations and electrons are generated. The ejected electron further induces ionization and reacts with acid generators after their energy has been lost sufficiently. Through the reaction with electrons, the acid generators release counter anions of acids. Protons of acids are generated through the deprotonation of polymer radical cations. Therefore, it is important to accomplish the uniformity of acid generators in polymer matrices in order to accomplish high sensitivity and ultra-fine pattern in EUV lithography.

As above-mentioned, the feature sizes are so shrinking that the uniformity of distribution of acid generators in resist matrices becomes a serious concern [12]. It is reported that phase separation, non-uniform acid distribution, and migration caused due to compatibility problem between the acid generator and the polymer matrix lead to an undesirable and non-uniform deprtection reaction in chemically amplified resist. [15] The best way to circumvent the compatibility problem of acid generators with polymer is obviously the incorporation of acid generators to polymers typically via covalent bonds. The incorporation of acid generator into polymers is expected to improve LER and get high resolution by reducing the diffusion lengths of acids. Many attempts to incorporate acid generators such as ionic and non-ionic PAGs into backbone or pendant groups of polymers have been reported mainly to circumvent the problem related to compatibility of acid generators or to suppress acid diffusion in resist matrices. [16-34]

It is very important to know whether a polymer bound PAG provides a substantial advantage over polymer blended PAG in terms of resolution, sensitivity, LWR tradeoffs. Up to now, it is known that the polarity and hydrophobicity of the polymer were very different from those of the polymer when the acid generators were incorporated into polymers. However, understanding of the resist dissolution kinetics in polymer-bounded and polymer-blended photo-acid generator (PAG) for extreme ultraviolet (EUV) lithography is insufficient. In this study, the dissolution kinetics of polymers-bound and polymer-blended PAG was investigated using a resist development analyzer (RDA-800EUV) [35-36] measurement system (Litho Tech Japan). Also, the simulation of resist profiles for polymer-bounded and polymer-blended PAG was performed by calculation using PROLITH and the parameters obtained with EUV exposure tool. Furthermore, the resist patterns were produced by EB and the SEM observation results were compared with the PROLITH simulation results.

\section{Experimental}

In experiments, polymer bound PAG and polymer blended PAG resists were synthesized. Polymer bound PAG were composed of $10 \mathrm{~mol} \%$ triphenyl sulfonium fluoroalkyl sulfonatecontaining methacrylate monomer and polymer blended PAG were used as resist matrices as shown in Figure 1. Resists A and B were polymer-blended and polymer-bound PAG resists (10 mol\% PAG), respectively. Also, a new triphenylsulfonium-type acid generator (TPS-lAd) was used as an acid generator in polymer blended PAG. Cyclohexanone was used as casting solvents. The resist samples 


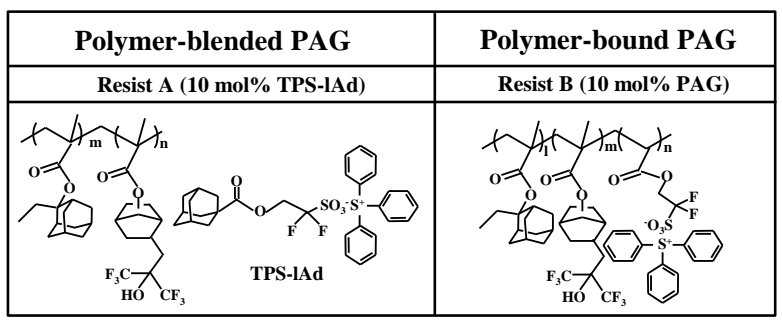

Fig. 1. Structure of polymer-blended and polymer-bound PAG resists.

were spin-coated onto silicon substrates at 3000 $\mathrm{rpm}$ for $30 \mathrm{~s}$ to form thin films and exposed to EUV radiation (Energetic, EQ-10M). The exposed area was approximately $1 \times 1 \mathrm{~cm}^{2}$. The exposure doses ranged from 0 to $5 \mathrm{~mJ} / \mathrm{cm}^{2}$. After the exposure, dissolution rate measurements were conducted at $110{ }^{\circ} \mathrm{C}$ for $60 \mathrm{~s}$ under PEB conditions within $1 \mathrm{~min}$ of intial exposure to minimize airborne contamination. They were developed in NMD-3 developer [2.38\% tetramethylammonium hydroxide (TMAH) solutions] for 30 s at $23{ }^{\circ} \mathrm{C}$ and the dissolution kinetics was investigated using a resist development analyzer (RDA) measurement system (Litho Tech Japan). For this analysis tool, the resist dissolution is obtained by measuring the thickness of resist films coated on $\mathrm{Si}$ before and after development. The dissolution rate was estimated by monitoring the variation in interference of a $470 \mathrm{~nm}$ wavelength light reflected at the $\mathrm{Si}$ substrate and resist film surface as resist film dissolve in TMAH developer. Resist film thickness was measured with a surface profiler.

Also, EUV lithography simulation was performed by using these data obtained with EUV exposure tools. Furthermore, the resist patterns were produced by $75 \mathrm{kV}$ electron beam. After the exposure, they were baked in the temperature range of $80-140{ }^{\circ} \mathrm{C}$ for $60 \mathrm{~s}$. They were immersion-developed in 2.38 wt $\%$ TMAH solutions for $30 \mathrm{~s}$ and rinsed in water before drying. Resist patterns were recorded with a Hitachi High technologies S-5500 SEM.

\section{Results and discussion}

The dissolution kinetics of polymers-bound and polymer-blended PAG was investigated. The development rate of resist films were measured by irradiating a developing resist thin films with monochromatic light. When the monochromatic light is incident on the developing resist films, the light reflected from Si substrate surface. As the resist film thickness changes sinusoidally. By using

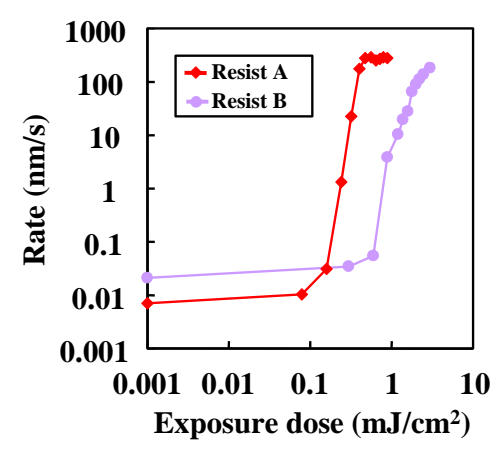

Fig. 2. Dissolution rate curves in Resist A and B. The curves relate the resist dissolution rate as a function of exposure dose on a $\log / \log$ scale.

a $470 \mathrm{~nm}$ light emitting diode (LED) light source, adequate interference waveforms could be obtained up to $80 \mathrm{~nm}$. Light reflected from the sample enters and passes through a receiving lens and optical fiber to a phototransistor and the output signal is digitized and analyzed by a computer. Figure 2 shows the dissolution rate curve in Resist A and B. The curves relate the resist dissolution rate as a function of exposure dose on a $\log / \log$ scale. The dissolution curve obtained is similar to those reported elsewhere. [37-40] The function of exposure dose on a $\log / \log$ scale have an $\mathrm{S}$ shape as shown in Figure 2. This implied that the dissolution rate change was very small in the low dose region, then abruptly increased at threshold dose, and finally converged to a constant rate. The sensitivity of the polymer-blended PAG resist is higher than that of the polymer-bound PAG resist when the resists are exposed to EUV. This is the reason why the acid diffusion of the polymer-blended PAG resist is longer than that of the polymer-bound PAG resist. The dissolution parameters such as maximum dissolution rate (Rmax) and minimum dissolution rate (Rmin) were obtained from Figure 2. The difference in $R \max$ was not observed between Resist A and B. On the other hand, Rmin decreased with binding of PAG with polymer. Binding of PAG to polymer was likely to provide decreased inhibition.
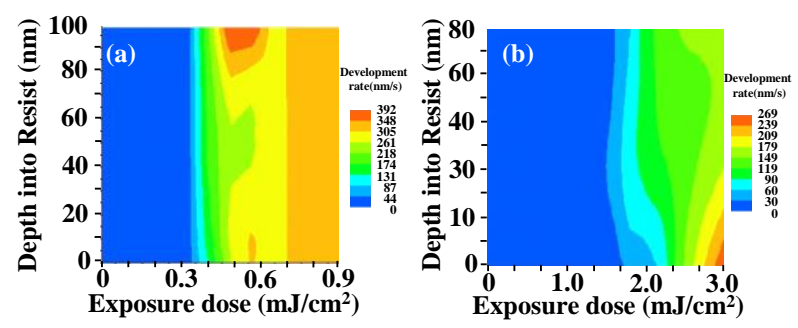

Fig. 3. Development rate $R(E, Z)$ at different depth position in (a) Resist A and (b) Resist B films. 
By converting the development time and reflected light intensity data into development rate date, the development rate $\mathrm{R}(\mathrm{E}, \mathrm{Z})$ at different depth positions in resist films could be determined for a rage of exposure doses. Figure 3 shows the development rate $\mathrm{R}(\mathrm{E}, \mathrm{Z})$ at different depth position in (a) Resist A and (b) Resist B films. Here, R is the development rate, $\mathrm{E}$ is the exposure dose, and $\mathrm{Z}$ is the depth in the resist film. The difference of $\mathrm{R}(\mathrm{E}, \mathrm{Z})$ in polymer-bounded and polymer-blended PAG was observed. The dissolution rates were affected by binding of PAG to polymer. The development rate of the polymer-bound PAG resist at different depth position is more uniform than that of the polymer-blended PAG resist. It has been reported that polymer-bound PAG materials are likely to exhibit a markedly different PAG distribution than a conventional blended PAG resist. [32] In our study, similar results were obtained. Thus, the polymer-bound PAG might give the uniform distribution of acid generated in resist matrices. These results show the polarity and hydrophobicity of the polymer-bound PAG resist were very different from those of the polymer when the acid generators were incorporated into polymers.

\begin{tabular}{|c|c|c|c|c|}
\hline Resist A & $0.5 \mathrm{~mJ} / \mathrm{cm}^{2}$ & $1.5 \mathrm{~mJ} / \mathrm{cm}^{2}$ & $2.5 \mathrm{~mJ} / \mathrm{cm}^{2}$ & $5 \mathrm{~mJ} / \mathrm{cm}^{2}$ \\
\hline $\begin{array}{c}\text { L\&S pattern } \\
30 \mathrm{~nm} \\
\text { Film thickness } \\
100 \mathrm{~nm}\end{array}$ & & & & \\
\hline $\begin{array}{c}\text { L\&S pattern } \\
50 \mathrm{~nm} \\
\text { Film thickness } \\
100 \mathrm{~nm}\end{array}$ & & & & \\
\hline Resist B & $0.5 \mathrm{~mJ} / \mathrm{cm}^{2}$ & $1.5 \mathrm{~mJ} / \mathrm{cm}^{2}$ & $2.5 \mathrm{~mJ} / \mathrm{cm}^{2}$ & $5 \mathrm{~mJ} / \mathrm{cm}^{2}$ \\
\hline $\begin{array}{c}\text { L\&S pattern } \\
30 \mathrm{~nm} \\
\text { Film thickness } \\
80 \mathrm{~nm}\end{array}$ & & & & \\
\hline
\end{tabular}

Fig. 4. $30 \mathrm{~nm} L \& S$ pattern profiles of Resist A and Resist B, calculated by PROLITH.

Furthermore, we performed EUV lithography simulation by using the development rate data of Resist A and B obtained with EUV exposure tools. The partially coherence factor of the illumination system was 0.5 . The resist line width was set to 30 $\mathrm{nm}$ 1:1 line\& space pattern. The exposure dose is set to $0.5,1.5,2.5$, and $5 \mathrm{~mJ} / \mathrm{cm}^{2}$. At the film thickness of $30 \mathrm{~nm}$ and $50 \mathrm{~nm}$, an almost vertical is obtained for Resist A less than $1.5 \mathrm{~mJ} / \mathrm{cm}^{2}$. Also, good quality patterns were obtained for Resist B at film thickness of $30 \mathrm{~nm}$ as shown in Figure 4. Thus, the developed resist were expected to show excellent performance.

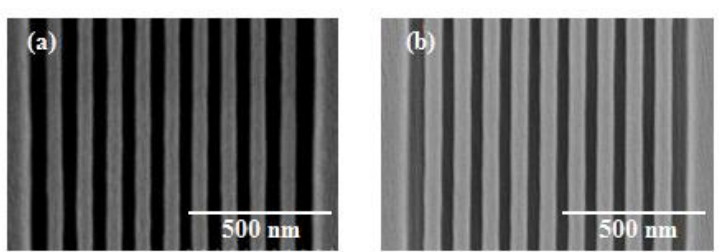

Fig. 5. SEM image of L\&S pattern in (a) Resist A and (b) Resist B by using $75 \mathrm{kV}$ EB.

Finally, the patterning of Resist A and Resist B was performed using EB. Figures 5(a) and 5(b) show the top-down SEM micrographs of the line and space patterns delineated on $10 \mathrm{~mol} \%$ polymer-blended and polymer-bound PAG resists [(a)Resists A and (b) ResistB], respectively. These patterns (40 $\mathrm{nm}$ line and $100 \mathrm{~nm}$ pitch) required the dose of $40 \mu \mathrm{C} / \mathrm{cm}^{2}$. These patterns required a 100 ${ }^{\circ} \mathrm{C}$ PEB treatment for $60 \mathrm{~s}$. The developed resist showed an excellent performance although optimization of processing conditions and resolution limitation were not performed. PROLITH might suggest the possibility of rough examination of resolution for EUV resist.

\section{Conclusion}

Polymer-blended and polymer-bound PAG effects on the dissolution kinetics were investigated to understand inherent EUV resist characteristics. The sensitivity of the polymer-blended PAG resist is higher than that of the polymer-bound PAG resist when the resists are exposed to EUV. This is the reason why the acid diffusion of the polymer-blended PAG resist is longer than that of the polymer-bound PAG resist. The difference of $\mathrm{R}(\mathrm{E}, \mathrm{Z})$ in polymer-bounded and polymer-blended PAG was observed. Binding of PAG to polymer was likely to provide decreased inhibition. The dissolution rates were affected by binding of PAG to polymer. The development rate of the polymer-bound PAG resist at different depth position is more uniform than that of the polymer-blended PAG resist. Thus, the polymer-bound PAG might give the uniform distribution of acid generated in resist matrices. Also, we performed EUV lithography simulation by using PROLITH. The developed resist were expected to show excellent performance from PROLITH. Actually, they showed an excellent performance by EB performance estimation although optimization of processing conditions and resolution limitation were not performed. 


\section{Acknowledgement}

The authors wish to thanks Dr. Kazuhiko Maeda and Dr. Koichi Miyauchi at Central Glass Corporation, Ltd. for generosity in providing resist materials for our research. Also, the authors wish to thank Dr. Atsushi Sekiguchi at Litho Tech Japan Co for useful advice and help as for PROLITH.

\section{References}

1. International Technology Roadmap for Semiconductors 2008 update. http://www.itrs.net/ Links/2008ITRS/Update/2008Tables_FOCUS_B .xls

2. G. M. Gallatin, Proc. SPIE, 5754, 38 (2005).

3. H. Ito, Adv. Polym. Sci., 172, 37 (2005)

4. H. Yamamoto, A. Nakano, K. Okamoto, T. Kozawa, and S. Tagawa, Jpn. J. Appl. Phys., Part 1 43, 3971 (2004).

5. H. Yamamoto, T. Kozawa, A. Nakano, K. Okamoto, S. Tagawa, T. Ando, M. Sato, and H. Komano, J. Vac. Sci. Technol., B 23, 2728 (2005).

6. H. Yamamoto, T. Kozawa, A. Nakano, K. Okamoto, S. Tagawa, T. Ando, M. Sato, and H. Komano, Jpn. J. Appl. Phys., Part 1 44, 5836 (2005).

7. T. Kozawa, Y. Yoshida, M. Uesaka, and S. Tagawa, Jpn. J. Appl. Phys., Part 1 31, 4301 (1992).

8. T. Kozawa, S. Tagawa, H. Oizumi, and I. Nishiyama, J. Vac. Sci. Technol., B24, L27 (2006).

9. H. Yamamoto, T. Kozawa, S. Tagawa, H. B. Cao, H. Deng, and M. J. Leeson, Jpn. J. Appl .Phys., 46, L142 (2007).

10 H. Ito and C. G. Willson: Polym. Eng. Sci., 23, 1012 (1983).

11 H. Ito, Adv. Polym. Sci., 37, 172 (2005).

12 D. R. McKean, R. D. Allen, P. H. Kasai, U. P. Schaedeli, and S. A. MacDonald: Proc. SPIE, 1672, 94 (1992).

13 H. Yamamoto, T. Kozawa, A. Nakano, K. Okamoto, S. Tagawa, T. Ando, M. Sato, and H. Komano: Jpn. J. Appl. Phys., 44, 5836 (2005).

14 J. L. Lenhart, D. A. Fischer, S. Sambasivan, E. K. Lin, R. L. Jones, C. L. Soles, W. Wu, D. L. Goldfarb, and M. Angelopoulos: Langmuir, 21, 4007 (2005).

15 K. L. Covert, D. J. Russell, J. Appl. Polym. Sci., 49, 657 (2002).

16 R. D. Allen, U. Schaedeli, D. R. McKean, S. A. MacDonald, Polym. Mater. Sci. Eng., 61, 185 (1989).
17 J. E. Hanson, E. Reichmanis, F. M. Houlihan and T. X. Neenan, Chem. Mater., 4, 837 (1992).

18 G. M. Wallraff and W. D. Hinsberg, Chem. Rev., 99, 1801 (1999).

19 M. D. Stewart, H. V. Tran, G. M. Schmid, T. B. Stachowiak, D. J. Becker and C. G. Willson, $J$. Vac. Sci. Technol., B 20, 2946 (2002).

20 N. N. Matsuzawa, H. Oizumi, S. Mori, S. Irie, E. Yano, S. Okazaki and A. Ishitani, Microelectron. Eng., 53, 671 (2000).

$21 \mathrm{H}$. Wu and K. E. Gonsalves, Adv. Funct. Mater., 11, 271 (2001).

$22 \mathrm{H}$. Wu and K. E. Gonsalves, Advence, Adv. Mater., 13, 195 (2001).

23 T. Shinozuka, M Shirai and M Tsunooka, Eur. Polym. J., 37 (2001) 1625.

24 M. D. Stewart, H. V. Tran, G. M. Schmid, T. B. Stachowiak, D. J. Becker and C. G. Willson, J. Vac. Sci. Technol., B 20, 2946 (2002).

25 M. Thiyagarajan, K. Dean and K. E. Gonsalves, J. Photopolym. Sci. Technol., 18, 737 (2005).

26 M. X. Wang, N. D. Jarnagin, C. T. Lee, C. L. Henderson, W. Yueh, J. M. Roberts and K. E. Gonsalves, J. Mater. Chem., 16, 3701 (2006).

27 M. X. Wang, K. E. Gonsalves, W. Yueh, J. M. Roberts, Macromol. Rapid Commun., 27 , 1590 (2006).

28 T. Watanabe, Y. Fukushima, H. Shiotani, M. Hayakawa, S. Ogi, Y. Endo, T. Yamanaka, S. Yusa and H. Kinoshita, J. Photopolym. Sci. Technol., 19, 521 (2006).

29 M. X. Wang, K. E. Gonsalves, M. Rbinovich, W. Yueh and J. M. Roberts, J. Mater. Chem., 17, 1699 (2007).

30 C. T. Lee, C. L. Henderson, M-X. Wang, K. E. Gonsalves and W. Yueh, J. Vac. Sci. Technol., B 25, 2136 (2007).

31 K. E. Gonsalves, M. Wang, C-T. Lee, W. Yueh, M. T-T, N. Batina and C. L. Henderson $J$. Mater. Chem., 19, 2797 (2009).

32 R. D. Allen, P. J. Brock, Y, H. Na, M. H. Sherwood, H. D. Truong, G. M. Wallraff, M. Fujiwara, K. Maeda J. Photopolym. Sci. Technol., 22, 25 (2009).

33 R. Gronheid, A. Vaglio Pret, B. Rathsack, J. Hooge, S. Scheer, K. Nafus, H. Shite and J. Kitano, Proc. SPIE, 7639, 76390M-1 (2010).

34 S. Tarutani, H. Tamaoki, H. Tsubaki, T, Takahashi, H. Takizawa, and H. Takahashi $J$. Photopolym. Sci. Technol., 24, 185 (2011).

35. A. Sekiguchi, C. A. Mack, Y. Minami and T. Matsuzawa, Proc. SPIE, 2725, 49 (1996). 
36. A. Sekiguchi, Y. Kono, M. Kadoi, Y. Minami, T. Kozawa, S. Tagawa, D. Gustafson and P. Blackborow, Proc. SPIE, 6519, 651946-1 (1996).

37. T. Itani, K. Kaneyama, T. Kozawa and S. Tagawa, J. Vac. Sci. Technol., B26, 2261
(2008).

38. T. Itani, H. Iwasaki, H. Yoshino, M. Fujimoto and K. Kasama, Proc. SPIE, 2195, 126 (1994).

39. T. Itani, H. Iwasaki, H. Yoshino, M. Fujimoto and K. Kasama, Proc. SPIE, 2438, 191 (1995).

40. H. Ito, IBM J. Res. Develop.. 45683 (2001). 